\title{
Comentário
}

\section{Psiquiatria e planos de saúde}

Há uma grande expectativa em relação à nova situação criada com a regulamentação da cobertura da assistência à saúde pelos planos e seguros privados. A Lei 9.656, de 3 de junho de 1998, alterada pela Medida Provisória (MP) 1.801, já está em vigor no país e prevê que as operadoras têm prazo até o dia 3 de dezembro de 1999 para se adequarem às novas regras do setor. Este, portanto, é um ano de transição. Por isso, este período é muito importante, pois nele estão sendo debatidos aspectos reguladores, amplitudes de procedimentos a serem cobertos, custos etc.

A psiquiatria tem bons motivos para comemorar, pois foi incluída entre os procedimentos a serem cobertos de uma maneira nova, ou seja, tratada paritariamente com outros procedimentos médicos. Além disso, também aparece a psicoterapia como um procedimento, não exclusivamente, mas também médico, a ser obrigatoriamente coberto no Plano Básico.

Outro resultado positivo é o de que esta inclusão forçou o debate aberto entre os representantes da psiquiatria, do Ministério da Saúde e das seguradoras sobre o tema da psiquiatria e da saúde mental. Isto ocorreu antes da publicação das resoluções do Consu de 3 de novembro de 98, órgão criado pela Lei 9.656, que regulamentam o setor. O Ministério da Saúde está coordenando os grupos que estão normatizando o Rol de Procedimentos e Eventos a serem cobertos, entre estes o Grupo da Psiquiatria e da Saúde Mental. O andamento dos trabalhos está adiantado, e algumas questões ainda obscuras estão sendo debatidas. Este grupo inclui representantes das operadoras, dos hospitais, das Misericórdias, das entidades médicas (representadas pelo CFM), dos consumidores, dos odontólogos e da Unimed e tem se reunido em Brasília a cada 20 dias.

A ABP participou ativamente da inclusão de uma lista de procedimentos psiquiátricos na nova LPM da AMB que foi recentemente publicada. Além da consulta, foram incluídos procedimentos psicoterápicos, periciais e eletroconvulsoterapia. Este fato é de grande importância, pois, embora os planos de saúde não paguem valores de acordo com a LPM, a utilizam como referência de procedimentos avalizados pela AMB. Como psicoterapia não figurava como procedimento médico até o ano passado, os colegas principalmente mais novos vinham tendo dificuldades de se credenciarem junto a operadoras, como a Unimed. A LPM, portanto, dá cobertura para que, nas discussões com os representantes dos planos de saúde, os procedimentos psiquiátricos sejam defendidos com maior base.

É fundamental que estas ações junto ao Ministério da Saúde, que têm como meta garantir a cobertura aos procedimentos psiquiátricos, sejam acompanhadas por outras no âmbito médico sindical. As associações médicas, através dos seus departamentos de convênios, os sindicatos médicos e os conselhos regionais de medicina devem se organizar rapidamente e eficientemente para assegurar que a prestação de serviços médicos seja realizada dentro dos padrões éticos e de qualidade que a medicina dispõe, incluindo o pagamento digno aos profissionais de saúde.

Rogério Wolf de Aguiar Coordenador Nacional Grupo do Rol de Procedimentos e Eventos da Área da Saúde Mental 